\title{
Study of Anthropometric Measurements of the Anterior Ethmoidal Artery using Three- dimensional Scanning on 300 Patients
}

\author{
Vinicius Tomadon Bortoli ${ }^{1}$ Rafael Ferri Martins ${ }^{1} \quad$ Krystal Calmeto Negri $^{1}$ \\ ${ }^{1}$ IPO - Hospital Paranaense de Otorrinolaringologia LTDA - Núcleo de \\ Ensino e Pesquisa, Curitiba, Paraná, Brazil \\ Address for correspondence Vinicius Tomadon Bortoli, IPO - Hospital \\ Paranaense de Otorrinolaringologia LTDA - Núcleo de Ensino e \\ Pesquisa, Av. República Argentina, 2069 Agua Verde, Curitiba, Paraná \\ Int Arch Otorhinolaryngol 2017;21:115-121. \\ 80620010, Brazil (e-mail: viniciustbortoli@gmail.com).
}

\begin{abstract}
Introduction The anterior ethmoidal artery (AEA) is one of the main arteries that supply both the nasal mucosa and the ethmoid sinuses. The AEA shows variability regarding its distance from adjacent structures. Several studies have developed techniques to identify the AEA.

Objective This study aimed to compare the measurements from the AEA to the ethmoid bulla and to the frontal beak by using computed tomography of the face, while identifying their intraindividual and interindividual variations.

Methods We analyzed $300 \mathrm{CT}$ scans of the face performed at the CT scan Center at Hospital. The average age of subjects was $36 \pm 15.1$ years (range 4-84).

Results We found that the average distance from the AEA to the ethmoid bulla was $17.2 \pm 1.8 \mathrm{~mm}$ and the distance from the AEA to the frontal beak was $15.1 \pm 2.2 \mathrm{~mm}$. Regarding the average distance from the AEA to the frontal beak (AEA-frontal beak), there was a difference between the right and left sides, with the former being $0.4 \mathrm{~mm}$ higher on average than the latter. Among the age groups, there was a significant

Keywords

- ethmoid sinus

- anatomy

- cone-beam

- computed tomography

difference of distances between the AEA and the ethmoid bulla (AEA-ethmoid bulla), which were shorter in the $\leq 12$ years group. There was a positive and significant correlation between both measurements analyzed, with low values (high) of AEAethmoid bulla distance corresponding to low values (high) of AEA-frontal beak distance. Conclusion The measurements obtained adds anatomical knowledge that can serve as a parameter in frontal and ethmoid sinus surgery.
\end{abstract}

\section{Introduction}

The shape and size of paranasal sinuses are probably the most variable of all anatomical structures of the body. ${ }^{1}$ To ensure the safety and effectiveness of the nasal endoscopic surgery, both the knowledge of sinonasal cavity structures and attention to the main anatomical landmarks are essential. ${ }^{2-5}$

The ethmoidal artery is a branch of the ophthalmic artery and one of the main arteries to supply the nasal mucosa and ethmoid sinuses. ${ }^{6,7}$ It gives off meningeal branches on its way in the olfactory fossa, going down to the nasal cavity, where it supplies the anterior third of the nasal septum and the lateral wall of the nose. ${ }^{8}$ The anterior ethmoidal artery (AEA) goes through the orbit and the ethmoidal cells, and then gets into the olfactory fossa through the anterior ethmoidal groove of the lamina cribrosa. ${ }^{8,9}$

Locating the AEA is important for the identification of the frontal sinus recess, as well as for the determination of the skull base in endonasal surgery. ${ }^{2}$ Its location is variable in terms of distance from the frontal sinus and the skull received

May 16, 2016

accepted

November 3, 2016

published online

February 13, 2017
DOI http://dx.doi.org/

10.1055/s-0037-1598598. ISSN $1809-9777$.
Copyright $\odot 2017$ by Thieme-Revinter

Publicações Ltda, Rio de Janeiro, Brazil
License terms

(c) (i) $\ominus$ (\$) 
base, ${ }^{4,9,10}$ which makes it potentially vulnerable to lesions in nasal surgery procedures. Most AEA bleedings are not as difficult to handle as one might imagine, ${ }^{11}$ provided they are properly identified. ${ }^{12}$ When completely severed, however, the AEA may retract to the inside of the orbit and continue to bleed, resulting in retrobulbar hemorrhage. ${ }^{6,13}$ The progression causes loss of visual acuity or even amaurosis if orbital decompression is not performed. ${ }^{11}$ Lesion to the middle portion of the AEA, where it gets into the lateral lamella of the lamina cribrosa, may lead to CSF fistula. ${ }^{13}$ The AEA embolization is dangerous, because it can cause retrograde migration of particles to the ophthalmic artery with risk of blindness. $^{14}$

Several studies have developed techniques to facilitate AEA identification, either through CT scan analyses or cadaver dissection. Many landmarks for distance have been tested, such as the anterior nasal spine, the axilla of the middle turbinate, the lacrimal crest, and the frontal recess. $^{2,4,6,8,13,15}$

The aim of this study was to analyze and compare the measurements from the AEA to the ethmoid bulla and to the frontal beak through facial CT scan, while identifying their intraindividual and interindividual variations.

\section{Methods}

A retrospective study of 300 facial CT scans performed between January $2^{\text {nd }}$ and March $2^{\text {nd }}, 2015$, in the CT Scan Center of an ENT Hospital in the city of Curitiba, Paraná, Brazil. The images were taken through a Cone Beam iCat-1 equipment (Sciences International, Hatfield, USA), and the thickness of the tomographic cuts was $0.25 \mathrm{~mm}$.

The exclusion criteria were the following: age below 4 years; previous endonasal surgery with removal of ethmoid bulla; nasal tumors; craniofacial anomalies; facial fractures; rhinosinusitis or severe polyposis that makes it difficult to visualize the bone trabeculae through CT scan.

A single observer analyzed CT scan examinations with the use of the Arya software, which is part of the Pixeon PACS Aurora. The software shows the three planes simultaneously (axial, coronal, and sagittal) and allows taking measurements in the actual scale.

For the taking of measurements, we followed the steps below:

$1^{\text {st }}$ ) In the coronal plane, the anterior ethmoidal foramen was identified on the orbit wall. The ethmoidal artery was marked with a three-dimensional finder (-Fig. 1).

$2^{\text {nd }}$ ) In the parasagittal plane, two measurements were taken from the AEA: up to the most superior and anterior point of the ethmoid bulla ( $\overline{A E A-\text { Ethmold bulla }}$ distance); up to the most inferior and posterior point of the frontal beak ( $\overline{\text { AEA - Frontal beak }}$ distance) (-Fig. 2).

$3^{\text {rd }}$ ) The procedure was repeated on the left side, and the distance measurements of both sides (right and left) were taken.

We also collected information on the age and gender of the patients studied through CT scans, for better understanding of

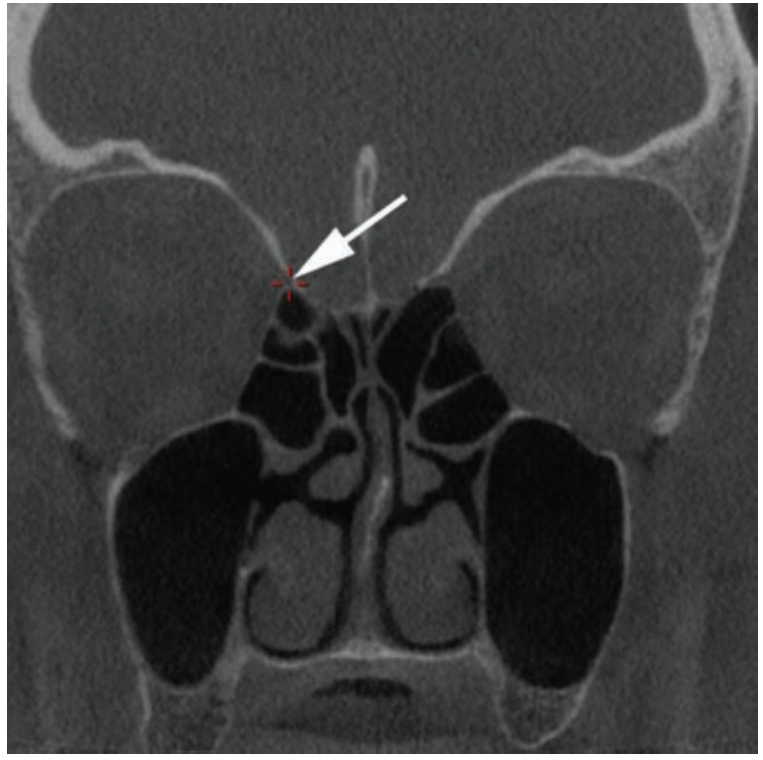

Fig. 1 Right ethmoidal foramen (arrow).

the sample. We divided them into 6 groups according to age: $\leq 12$ years, $12.1-20$ years, $20.1-30$ years, $30.1-40$ years, 40.1 to 60 years, and $>60$ years.

We input the data collected into a data sheet. We describe the results of quantitative variables by averages, medians, minimum values, maximum values, and standard deviations. We described qualitative variables through absolute and relative frequency distributions. We used the Student's $t$-test for paired samples in the comparison between the right and left sides regarding the CT scan measurements analyzed. We compared groups defined by age with respect to the CT scan measurements while taking into account the analysis of variance model (ANOVA) with one factor and the LSD test (least significant difference) for the multiple post-hoc

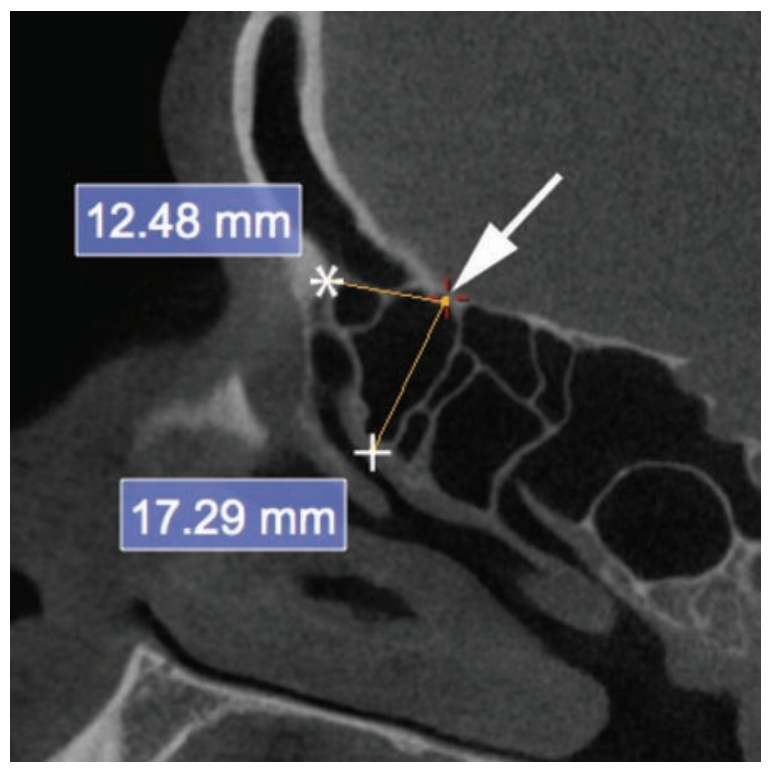

Fig. 2 Right ethmoidal foramen (arrow); Frontal beak (*); Ethmoid bulla (+). 
comparisons. We compared groups defined by gender with the use of the Student's $t$-test for independent samples. We estimated the Pearson's correlation coefficient for the analysis of the association between two quantitative variables. Values of $p<0.05$ show statistical significance. We analyzed data with the IBM SPSS Statistics v.20 computer software.

The Hospital Ethics Committee of Research in Human Beings approved the study under registration number 0077/2015 and CAAE 46735515.0.0000.5529.

\section{Results}

We analyzed the facial CT scans of 300 patients, out of which 121 (40.3\%) were men and 179 (59.7\%) women. The average age was $36 \pm 15.1$ years, range $4-84$.

The distances from the anterior ethmoidal artery in relation to the ethmoid bulla and the frontal beak are available in - Table 1. - Fig. 3 shows the frequency distributions and descriptive statistics of average, standard deviation, minimum, and maximum values of each of the measurements analyzed, while taking into account the average of measurements taken on both the right and left sides (Average $\mathrm{R} / \mathrm{L}$ ). The average distance $\overline{A E A-\text { Ethmold bulla }}$ was $17.2 \pm$ $1.8 \mathrm{~mm}$ and the $\overline{A E A-\text { Frontal beak }}$ distance was $15.1 \pm$ $2.2 \mathrm{~mm}$.

When comparing right and left measurements, the results of statistical tests pointed out that there is no significant difference between the sides regarding the $\overline{A E A-E t h m o l d ~ b u l l a}$ average, and there is a significant difference between the sides regarding the $\overline{\text { AEA - Frontal beak }}$ average (-Table 2 ). In the latter, we observed a higher average on the right side than on the left side, with an average difference of $0.4 \mathrm{~mm}$ (-Fig. 4).

While taking 5 age groups into account, for each one of the $\overline{A E A-E t h m o l d ~ b u l l a}$ and $\overline{A E A-\text { Frontal beak }}$ measurements, we tested the null hypothesis of them being equal versus the alternative hypothesis of at least one of the age groups having a different average from the others ( - Table 3

Table 1 Distance measurements from anterior ethmoidal artery (AEA) to ethmoid bulla and to the frontal beak

\begin{tabular}{|c|c|c|c|c|c|c|c|c|c|c|c|c|c|}
\hline \multirow{2}{*}{$\begin{array}{l}\text { AEA-ethmoid } \\
\text { bulla (mm) }\end{array}$} & \multicolumn{2}{|c|}{ Right } & \multicolumn{2}{|l|}{ Left } & \multicolumn{2}{|c|}{ Average $\mathrm{R} / \mathrm{L}$} & \multirow{2}{*}{$\begin{array}{l}\text { AEA-Frontal } \\
\text { beak (mm) }\end{array}$} & \multicolumn{2}{|c|}{ Right } & \multicolumn{2}{|l|}{ Left } & \multicolumn{2}{|c|}{ Average $R / L$} \\
\hline & $\mathrm{n}$ & $\%$ & $\mathbf{n}$ & $\%$ & $n$ & $\%$ & & $n$ & $\%$ & $n$ & $\%$ & $n$ & $\%$ \\
\hline 10 to 12 & 1 & 0.3 & 2 & 0.7 & 1 & 0.3 & 8 to 10 & 0 & 0 & 2 & 0.7 & 1 & 0.3 \\
\hline 12.1 to 14 & 19 & 6.3 & 21 & 7.0 & 14 & 4.7 & 10.1 to 12 & 20 & 6.7 & 31 & 10.3 & 20 & 6.7 \\
\hline 14.1 to 16 & 63 & 21.0 & 65 & 21.7 & 66 & 22.0 & 12.1 to 14 & 74 & 24.7 & 72 & 24.0 & 76 & 25.3 \\
\hline 16.1 to 18 & 111 & 37.0 & 102 & 34.0 & 121 & 40.3 & 14.1 to 16 & 93 & 31.0 & 102 & 34.0 & 103 & 34.3 \\
\hline 18.1 to 20 & 78 & 26.0 & 93 & 31.0 & 81 & 27.0 & 16.1 to 18 & 77 & 25.7 & 64 & 21.3 & 69 & 23.0 \\
\hline 20.1 to 22 & 27 & 9.0 & 14 & 4.7 & 17 & 5.7 & 18.1 to 20 & 27 & 9.0 & 23 & 7.7 & 24 & 8.0 \\
\hline 22.1 to 24 & 1 & 0.3 & 3 & 1.0 & 0 & 0 & 20.1 to 22 & 6 & 2.0 & 4 & 1.3 & 5 & 1.7 \\
\hline & & & & & & & 22.1 to 24 & 3 & 1.0 & 2 & 0.7 & 2 & 0.7 \\
\hline Total & 300 & 100 & 300 & 100 & 300 & 100 & Total & 300 & 100 & 300 & 100 & 300 & 100 \\
\hline
\end{tabular}
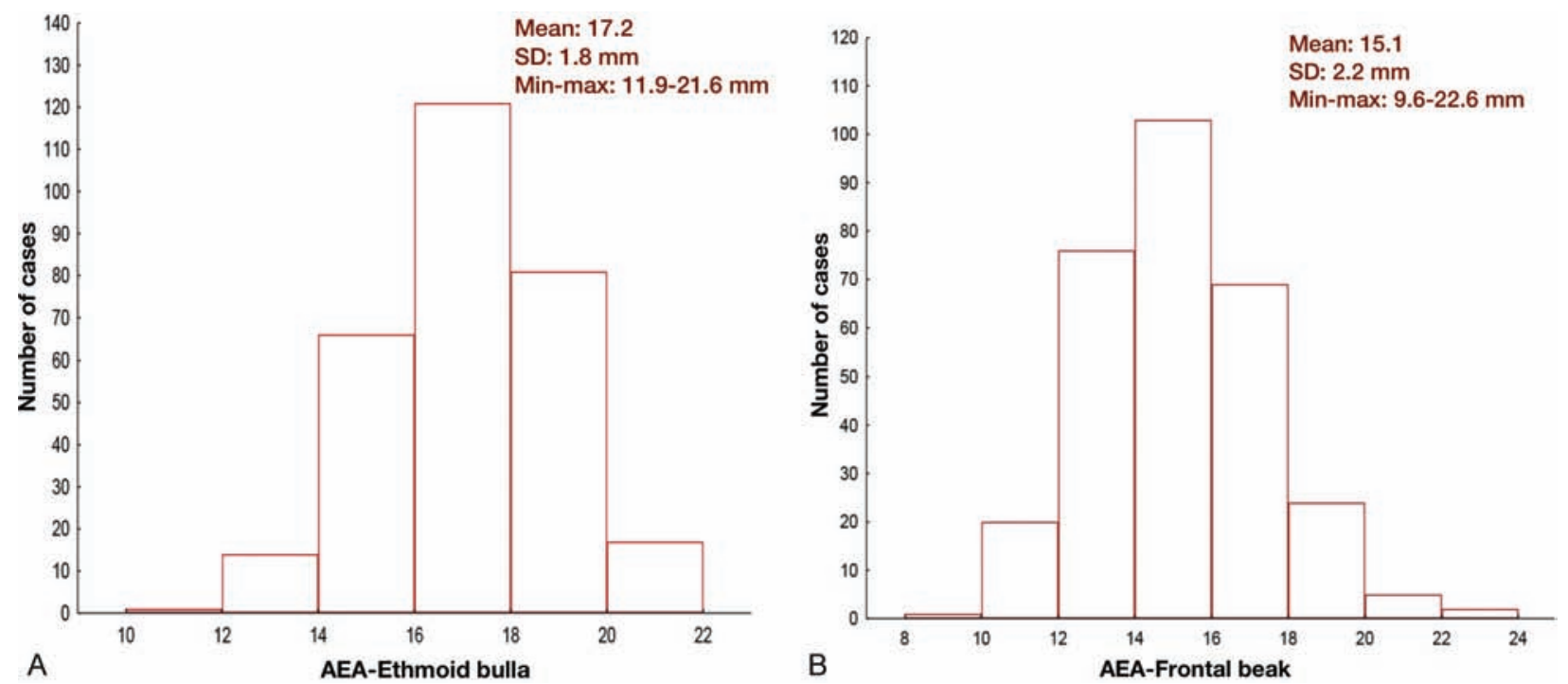

Fig. 3 (A) Averages R/L from anterior ethmoidal artery (AEA) to ethmoid bulla. (B) Averages R/L from AEA to frontal beak 
and - Fig. 5). For the $\overline{A E A-E t h m o l d ~ b u l l a}$ measurement, in both sides, we found significant difference among the age groups. We observed that the distance values are smaller in the $\leq 12$ years group compared with the other groups. For the $\overline{A E A-\text { Frontal beak }}$ measurement, we found no significant difference among the age groups.

As for the genders, we analyzed the null hypothesis versus the alternative, whereby the $\overline{A E A-\text { Ethmoid bulla }}$ and $\overline{A E A-\text { Frontal beak }}$ measurements are equal or different (-Table 4). The results pointed out that there is no significant difference between genders regarding the measurements analyzed.

We tested the null hypothesis that there is no association between the $\overline{A E A-\text { Ethmold bulla }}$ and $\overline{A E A-\text { Frontal beak }}$ measurements (correlation coefficient equals zero), versus the alternative hypothesis that there is an association (correlation coefficient different from zero). The estimated Pearson's correlation coefficient was 0.32 with $p<0.001$ (-Fig. 6). The results pointed out that there was a positive and significant correlation between the measurements analyzed, in other words, low values (high) of
$\overline{A E A-\text { Ethmoıd bulla }}$ correspond to low values (high) of $\overline{\text { AEA-Frontal beak }}$.

\section{Discussion}

The correct identification of the AEA at the preoperative stage helps to reduce complications that might occur in endonasal endoscopic surgeries, such as bleeding, retro-orbital hemorrhage, and CSF fistula. The CT scan analysis allows us to predict altered anatomical patterns that may cause difficulties at surgery.

Among the factors identified in data collection that influence the variability of the measurements studied are: AEA location (regarding adjacency to skull base or closeness to the frontal recess); degree of pneumatization of the frontal beak; size of ethmoid bulla; presence or absence of supraorbital cells; amount of cells between the ethmoid bulla; and the AEA.

Souza et $\mathrm{al}^{8}$ and Ding et $\mathrm{al}^{16}$ found the anterior ethmoidal foramen in $100 \%$ of CT scans, as we found in this study. Gotwald et al and MacDonald et al identified the anterior

Table 2 Comparison of anterior ethmoidal artery (AEA) measurements concerning laterality

\begin{tabular}{|l|l|l|l|l|l|l|l|l|}
\hline Measure (mm) & Side & $\mathbf{n}$ & Average & Median & Minimum & Maximum & SD & $\boldsymbol{p}^{*}$ \\
\hline \multirow{4}{*}{ AEA-Ethmoid bulla } & Right & 300 & 17.2 & 17.2 & 10.3 & 22.8 & 2.1 & - \\
\cline { 2 - 9 } & Left & 300 & 17.1 & 17.3 & 10.6 & 22.7 & 2.0 & - \\
\cline { 2 - 9 } & Dif (right - left) & 300 & 0.1 & -0.04 & -5.0 & 11.0 & 1.8 & 0.433 \\
\hline \multirow{4}{*}{ AEA-Frontal beak } & Right & 300 & 15.3 & 15.3 & 10.0 & 23.8 & 2.4 & - \\
\cline { 2 - 9 } & Left & 300 & 14.9 & 14.8 & 9.1 & 22.8 & 2.3 & - \\
\cline { 2 - 9 } & Dif (right - left) & 300 & 0.4 & 0.3 & -3.1 & 7.7 & 1.6 & $<0.001$ \\
\hline
\end{tabular}

*Student's $t$-test for paired samples, $p<0.05$.
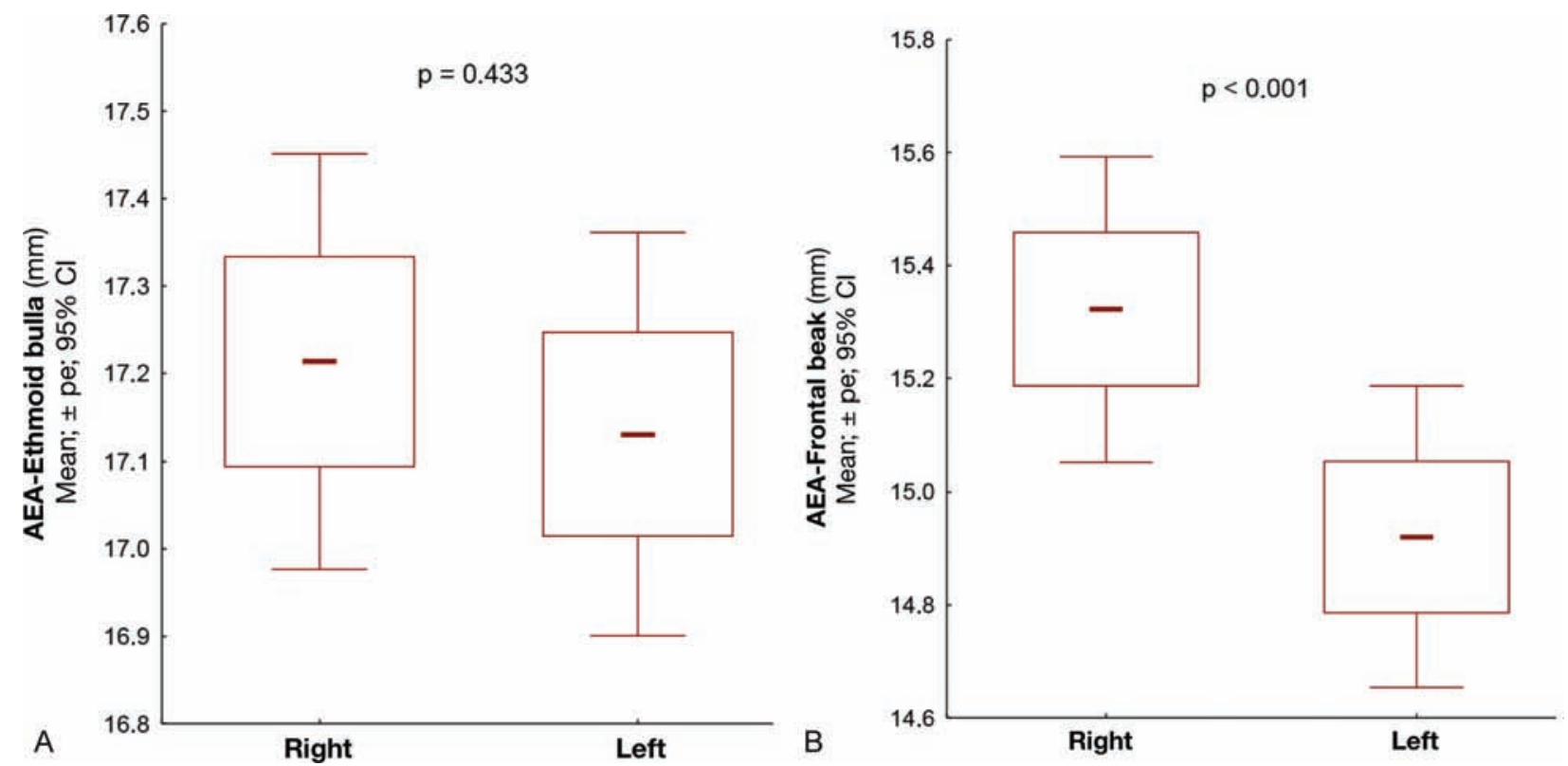

Fig. 4 (A) (Comparison of anterior ethmoidal artery (AEA) measurements concerning laterality. (B) Comparison of AEA measurements concerning laterality. 
Study of Anthropometric Measurements of the Anterior Ethmoidal Artery using 3-D Scanning Bortoli et al. 119

Table 3 Comparison of anterior ethmoidal artery (AEA) R/L averages concerning age

\begin{tabular}{|c|c|c|c|c|c|c|c|c|}
\hline Measure $(\mathrm{mm})$ & Age (years) & $n$ & Average & Median & Minimum & Maximum & SD & $p^{*}$ \\
\hline \multirow{6}{*}{$\begin{array}{l}\text { AEA } \\
\text { ethmoid bulla }\end{array}$} & $\leq 12$ & 9 & 15.0 & 14.9 & 12.6 & 18.8 & 2.1 & - \\
\hline & 12.1 to 20 & 30 & 17.1 & 17.0 & 15.0 & 21.6 & 1.6 & - \\
\hline & 20.1 to 30 & 79 & 17.3 & 17.4 & 12.9 & 21.5 & 1.7 & - \\
\hline & 30.1 to 40 & 92 & 17.6 & 17.7 & 13.4 & 21.1 & 1.7 & - \\
\hline & 40.1 to 60 & 65 & 16.7 & 17.1 & 11.9 & 20.4 & 2.0 & - \\
\hline & $>60$ & 25 & 17.2 & 17.7 & 13.6 & 20.8 & 2.0 & $<0.001$ \\
\hline \multirow{6}{*}{$\begin{array}{l}\text { AEA } \\
\text { frontal beak }\end{array}$} & $\leq 12$ & 9 & 14.6 & 14.1 & 12.1 & 17.2 & 1.9 & - \\
\hline & 12.1 to 20 & 30 & 15.4 & 15.4 & 10.8 & 20.1 & 2.4 & - \\
\hline & 20.1 to 30 & 79 & 15.3 & 15.2 & 9.6 & 22.5 & 2.4 & - \\
\hline & 30.1 to 40 & 92 & 15.2 & 14.9 & 11.0 & 22.6 & 2.1 & - \\
\hline & 40.1 to 60 & 65 & 14.8 & 14.5 & 10.4 & 20.4 & 2.1 & - \\
\hline & $>60$ & 25 & 14.9 & 15.2 & 11.4 & 19.1 & 2.3 & 0.563 \\
\hline
\end{tabular}

Abbreviations: SD, standard deviation.

*ANOVA with a $p<0.05$ factor.
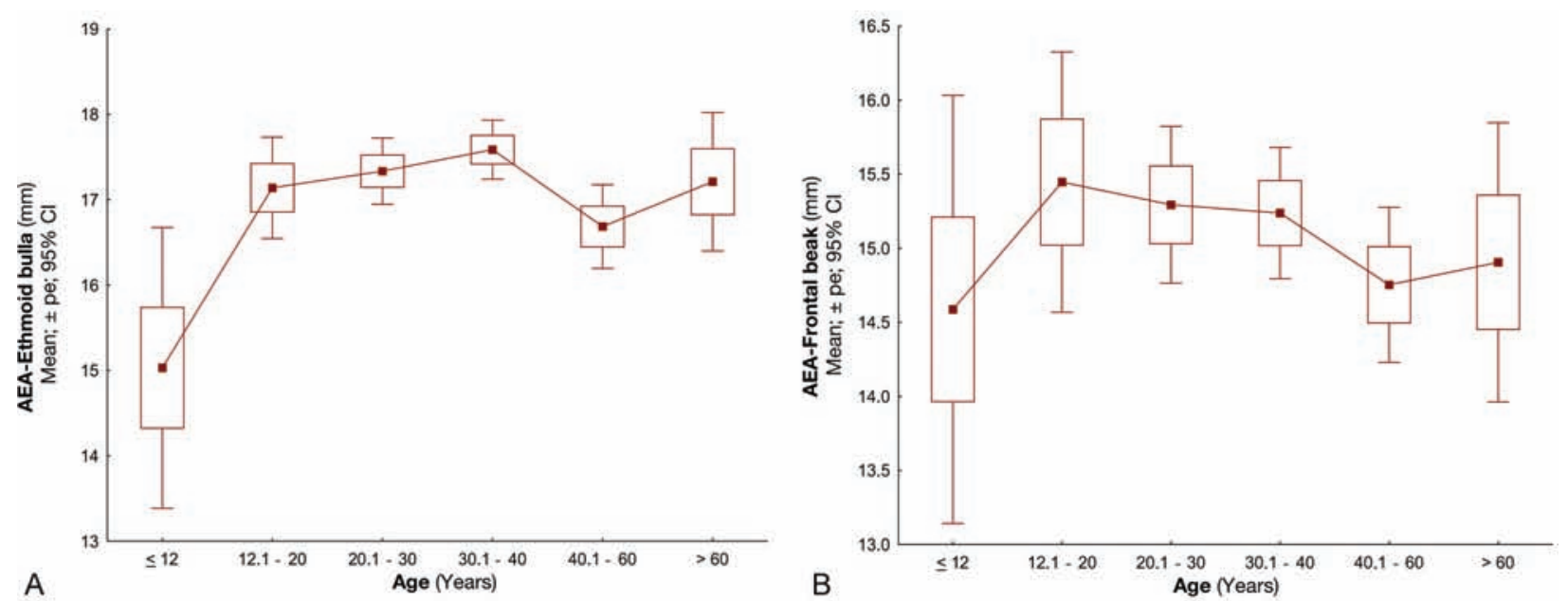

Fig. 5 (A) Comparison of anterior ethmoidal artery (AEA) R/L averages concerning age. (B) Comparison of AEA R/L averages concerning age.

Table 4 Comparison of anterior ethmoidal artery (AEA) R/L averages concerning sex

\begin{tabular}{|l|l|l|l|l|l|l|l|l|}
\hline Measure $(\mathbf{m m})$ & Sex & $\mathbf{n}$ & Average & Median & Minimum & Maximum & SD & $\boldsymbol{p}^{*}$ \\
\hline \multirow{2}{*}{ AEA-ethmoid bulla } & Fem & 179 & 17.1 & 17.2 & 12.4 & 21.5 & 1.8 & - \\
\cline { 2 - 9 } & Male & 121 & 15.2 & 14.8 & 10.4 & 22.6 & 2.3 & 0.283 \\
\hline \multirow{2}{*}{ AEA-Frontal beak } & Fem & 179 & 15.0 & 15.2 & 9.6 & 22.5 & 2.2 & - \\
\cline { 2 - 9 } & Male & 121 & 17.3 & 17.6 & 11.9 & 21.6 & 1.9 & 0.478 \\
\hline
\end{tabular}

Abbreviations: Min, minimum; Max, maximum; SD, standard deviation.

"Student's $t$-test for independent samples, $p<0.05$. 




Fig. 6 Scatter diagram showing correlation between the AEA-ethmoid bulla (anterior ethmoidal artery, AEA) and AEA-Frontal beak distances.

ethmoidal foramen in $95 \%$ of CT scans, ${ }^{8}$ and it remained questionable whether it was missing in the remaining ones or whether the tomographic cut skipped the structure. The ethmoidal foramen, therefore, is clearly visible and serves as an initial parameter for the identification of the AEA. When it is not possible to identify the AEA in a CT scan, it may be useful to repeat the examination by using a scan with a higher image resolution. ${ }^{13}$

In the endonasal endoscopic view, it is not possible to find the ethmoidal foramen as easily, and it is necessary to look for correlations between the AEA and other structures to make it possible for its safe identification. In a cadaveric study, after performing uncinectomy and anterior ethmoidectomy, Araújo Filho et $\mathrm{al}^{2}$ did not find the AEA in two nasal cavities among 25 corpses. It is unknown whether the AEA was missing or if it ran above the bone wall of the skull base.

With the aim to facilitate the identification of the AEA in endonasal surgeries, several studies have searched for correlations and measurements related to adjacent structures.

Stammberger et $\mathrm{al}^{11}$ reported that the AEA is $1-2 \mathrm{~mm}$ behind the junction of the posterior wall of the frontal recess with the adjacent anterior ethmoidal cell. Lund et al states that the posterior wall of the frontal recess is the landmark for the location of the AEA. ${ }^{2}$ In an endoscopic study, Simmen et $\mathrm{al}^{10}$ analyzed the distance between the AEA and the skull base coming to the conclusion that it is quite variable, and in the presence of supraorbital cells the artery is in a lower position, which increases the risk of lesion during surgery. In a tomographic study, Jang et $\mathrm{al}^{4}$ showed that the supraorbital cell, when present, is a consistent guide to identify the AEA even in cases of distorted anatomy of frontal recess.

Therefore, there are multiple links described between the AEA and adjacent structures, but none of them really show absolute practicality and reliability in a surgical procedure.

This study showed an average distance of $17.2 \pm 1.8 \mathrm{~mm}$ from the AEA to the ethmoid bulla. To the best of our knowledge, no study so far has conducted measurements between such structures. They generally analyze the link between the AEA location and the bulla or the third and fourth lamellas, but do not check absolute distances. ${ }^{3,10}$

As for the distances between the AEA and the frontal beak, Jang et $\mathrm{al}^{4}$ showed measurements of $17.36 \pm 2.19 \mathrm{~mm}$ in a tomographic study of 78 patients. They also analyzed CT scans with expanded supraorbital cells (due to fungus ball, mucocele, or polyposis) in which the average distance was $18.52 \pm 2.05 \mathrm{~mm}$. In our study, we found an average distance of $15.1 \pm 2.2 \mathrm{~mm}$. This average may have been reduced with the inclusion of patients aged 4-12 years in the sample, and not only adults.

Regarding genders, there was no significant difference for the analyzed measurements. As for laterality, there was no significant difference for the $\overline{A E A-E t h m o l d ~ b u l l a}$ measurements. For the $\overline{A E A-\text { Frontal beak }}$ one, however, the right side showed a higher average than the left one (average difference of $0.4 \mathrm{~mm}$ ), which, although statistically relevant, has no practical application due to it being a very small alteration.

According to literature, the viscerocranium is underdeveloped in newborns, while reaching $25 \%$ of its adult dimension at the end of the second year of age, and $50 \%$ by the end of the eighth year of age. ${ }^{1}$ In a cadaveric study, Isaacson et al showed that the midface growth is more accelerated up to the sixth year of life, and it continues to grow more slowly up to adulthood. ${ }^{17}$

In this study, we noticed that patients aged 4-12 years showed significantly smaller measurements between the AEA and the ethmoid bulla, but there was no significant difference in the measurements between the AEA and the frontal beak. This indicates that the growth process of the paranasal sinuses happens in such a way that the distance from the AEA to the ethmoid bulla may continue to grow even after the 12 years of age, which was not proven for the frontal beak distance. More studies need to be performed to analyze this possible association and to try to identify the growth rate of ethmoidal structures individually.

The study also showed that there is a correlation between the distance measurements from the AEA to the ethmoid bulla and to the frontal beak, which is that the bigger one of them is, the bigger the other one will be and vice-versa. We have not found in the literature an analysis of similar correlation.

\section{Conclusion}

Although there are multiple factors that play a part in the location of the AEA with respect to the ethmoid bulla and the frontal beak, the measurements taken in this study contribute to an anatomical knowledge that may serve as a parameter in frontal and ethmoidal sinus surgery. The greater the scientific knowledge on the connection between the AEA and its adjacent structures, the lower the probability of causing an inadvertent injury to a patient, while avoiding more important complications such as retrobulbar hematoma and CSF fistula. 
With such variability, however, those measurements are not to be used alone in the intraoperative stage. A previous study of each patient's CT scan is imperative.

\section{References}

1 Lorkiewicz-Muszyńska D, Kociemba W, Rewekant A, et al. Development of the maxillary sinus from birth to age 18 . Postnatal growth pattern. Int J Pediatr Otorhinolaryngol 2015;79(09):1393-1400

2 Araujo Filho BC, Weber R, Pinheiro Neto CG, Lessa MM, Voegels RL, Butugan O. Anatomia endoscópica da artéria etmoidal anterior: estudo de dissecção em cadáveres. Rev Bras Otorrinolaringol 2006;72(03):303-308

3 Lisbona Alquezar MP, Fernández Liesa R, Lorente Muñoz A, et al. [Anterior ethmoidal artery at ethmoidal labyrinth: Bibliographical review of anatomical variants and references for endoscopic surgery]. Acta Otorrinolaringol Esp 2010;61(03): 202-208

4 Jang DW, Lachanas VA, White LC, Kountakis SE. Supraorbital ethmoid cell: a consistent landmark for endoscopic identification of the anterior ethmoidal artery. Otolaryngol Head Neck Surg 2014;151(06):1073-1077

5 Wang L, Youseef A, Al Qahtani AA, et al. Endoscopic anatomy of the middle ethmoidal artery. Int Forum Allergy Rhinol 2014;4(02): 164-168

6 Vatanasapt P, Thanaviratananich S, Chaisiwamongkol K. Landmark of ethmoid arteries in adult Thai cadavers: application for sinus surgery. J Med Assoc Thai 2012;95(Suppl 11):S153-S156

7 White DV, Sincoff EH, Abdulrauf SI. Anterior ethmoidal artery: microsurgical anatomy and technical considerations. Neurosurgery 2005;56(2, Suppl)406-410, discussion 406-410
8 Souza SA, Souza MMA, Gregório LC, Ajzen S. Avaliação da artéria etmoidal anterior pela tomografia computadorizada no plano coronal. Rev Bras Otorrinolaringol 2009;75(01):101-106

9 El-Fiki M. Surgical Anatomy for Control of Ethmoidal Arteries During Extended Endoscopic Endonasal or Microsurgical Resection of Vascular Anterior Skull Base Meningiomas. World Neurosurg 2015;84(06):1532-1535

10 Simmen D, Raghavan U, Briner HR, et al. The surgeon's view of the anterior ethmoid artery. Clin Otolaryngol 2006;31(03): 187-191

11 Stammberger H, Posawetz W. Functional endoscopic sinus surgery. Concept, indications and results of the Messerklinger technique. Eur Arch Otorhinolaryngol 1990;247(02):63-76

12 Felippu A, Mora R, Guastini L. Endoscopic transnasal cauterization of the anterior ethmoidal artery. Acta Otolaryngol 2011;131(10): 1074-1078

13 Wong DK, Shao A, Campbell R, Douglas R. Anterior ethmoidal artery emerging anterior to bulla ethmoidalis: An abnormal anatomical variation in Waardenburg's syndrome. Allergy Rhinol (Providence) 2014;5(03):168-171

14 Cecchini G. Anterior and Posterior Ethmoidal Artery Ligation in Anterior Skull Base Meningiomas: A Review on Microsurgical Approaches. World Neurosurg 2015;84(04):1161-1165

15 Pernas FG, Coughlin AM, Hughes SE, Riascos R, Maeso PA. A novel use of a landmark to avoid injury of the anterior ethmoidal artery during endoscopic sinus surgery. Am J Rhinol Allergy 2011;25(01):54-57

16 Ding J, Sun G, Lu Y, et al. Evaluation of anterior ethmoidal artery by 320-slice CT angiography with comparison to three-dimensional spin digital subtraction angiography: initial experiences. Korean J Radiol 2012;13(06):667-673

17 Isaacson G, Monge JM. Arterial ligation for pediatric epistaxis: developmental anatomy. Am J Rhinol 2003;17(02):75-81 